\title{
REFLEXÕES E PROBLEMATIZAÇÕES SOBRE A PESQUISA EM EDUCAÇÃO FÍSICA: PERSPECTIVAS PARA OS ÓFILHOS DO CASAMENTO (IN)FELIZô
}

Cristiano Mezzaroba*

Fabio Zoboli**

\section{RESUMO:}

Este ensaio tem como objetivo estabelecer reflexões em torno das pesquisas no campo da Educação Física (EF) a partir de suas implicações históricas, considerando a divisão/diferenciação nas formações profissionais (licenciatura/bacharelado), cursos que neste texto fazemos alusão como sendo os r̃dois filhos do casamento (in)felizò que em plena ñuventudeò foram, por forças políticas e mercadológicas, afastados entre si, criando e sustentando dois nichos de pesquisa, de saberes e de intervenção no contexto da EF brasileira. Acreditamos ser necessário o diálogo respeitoso entre as partes no ato de se pesquisar numa área que ainda carece de seriedade acadêmica e profundidade teórica.

Palavras chave: Pesquisa em Educação Física. Licenciatura. Bacharelado.

\section{INTRODUÇÃO}

Entender o complexo, profundo e instigante processo de pesquisar como simples ñprodução do conhecimentoò pode se tornar uma idéia cara àqueles que, intencionalmente, colocam-se como agentes deste processo, independente da área/campo de conhecimento.

A pesquisa, como bem sabemos, é algo que transcende aquela representação social em torno do cientista: não basta colocarmos o jaleco

\footnotetext{
Mestre em Educação Física/UFSC, Professor Departamento de Educação Física ï Universidade Federal de Sergipe.

** Doutor em Educação/UFBA, Professor Departamento de Educação Física ï Universidade Federal de Sergipe.
} 
branco, acionarmos nossos instrumentos de trabalho (seja a prancheta e 0 bloco de anotações, ou mesmo aparelhos hightech para obtenção e processamento de dados) e redigirmos textos repletos de palavras e expressões rebuscadas, tabelas, gráficos e figuras que conotam a especificidade de uma determinada área (garantindo, com isso, a compreensão de uma parcela pequena, e, portanto, corporativista, daquilo que é produzido e socializado) para termos a garantia de que, enfim, realizamos uma pesquisa.

Pesquisar, no âmbito da Educação Física (EF), conforme nos alerta Vaz (1994), demanda o hábito do rigor, a fim de que toda e qualquer investigação que se pretenda útil, seja, em primeira instância, veículo de transformação social, legitimando um campo do saber e seus sujeitos, agentes produtores do conhecimento que, com o passar do tempo, vão garantindo, também, a legitimação de seu lócus científico, a partir da qualidade do que é produzido e socializado. Pesquisar, assim, é tornar claro o contexto histórico, teórico, político, filosófico e epistemológico de onde surge a investigação, seu processo e suas implicações. Tarefa, portanto, que pressupõe compromisso, comprometimento, responsabilidades e, acima de tudo, ética.

Neste texto refletiremos sobre a pesquisa na EF. Inicialmente fazemos alusão à EF como área do conhecimento que historicamente buscou sua identidade epistemológica com o status de ciência. Nesta parte do texto apresentamos o r̃casamento (in)felizò anunciado por Bracht (2007) quando o mesmo argumenta a tentativa frustrada que a EF fez para se tornar ciência, r̃casando-seòcom a ciência.

Em seguida, discute-se em torno da biologia como sendo a ciência-mãe da EF, o contexto histórico e as implicações disso atualmente, no caso, a hegemonia dos saberes/práticas biomédicos em relação à EF.

$\mathrm{Na}$ tentativa de anunciar possibilidades, continuamos as reflexões sugerindo aproximações da EF com as Ciências Sociais e Humanas (CSOH) ï aproximações estas que ocorreram, em especial, desde a década de 1980 e que hoje vemos se ampliar na EF brasileira.

Por último, as reflexões são sistematizadas em torno das implicações históricas ao campo da EF, ou seja, a divisão e diferenciação nas formações profissionais, entre licenciatura ï curso essencialmente pautado nas $\mathrm{CSOH}$ ï e o bacharelado ï essencialmente pautado nas ciências biológicas e naturais. 
Aqui fazemos alusão a estes cursos como os r̃dois filhos de um casamento (in)felizò em consonância ao texto de Bracht (2007), os quais vemos como filhos que em plena juventude foram, por forças políticas e mercadológicas, afastados entre si criando e sustentando dois nichos de pesquisa, de saberes e de intervenção no contexto da EF brasileira.

\section{EF: ALGUNS CONSENSOS EPISTEMOLÓGICOS?}

Os últimos anos do século passado e os primeiros anos deste novo milênio foram permeados por vários questionamentos no contexto da EF brasileira no que tange as questões de cunho epistemológico. ñComo falar de EF frente aos ecos de sua crise epistemológica e científica? Qual o objeto de estudo da EF? A EF está a reboque de outras ciências? Como situar problemas e contendas presentes na EF que são originalmente problematizações e discussões de outras áreas do conhecimento e ciências?ò Todas essas foram questões que pautaram debates que contribuíram sobremaneira para que a EF caminhasse alguns passos à frente na busca de sua identidade acadêmica enquanto campo/área do conhecimento.

Frente a estes litígios acreditamos que muito já se tenha discutido e parece que alguns consensos já foram consolidados. Valter Bracht em sua obra intitulada ז̃Educação Física e ciência: cenas de um casamento (in)felizò estabelece um diálogo tensivo interessante no que concerne a relação da EF com sua busca pelo status de ciência. Ao final Bracht (2007) chega à conclusão de que ciência e EF não tiveram uma relação de amor interessante, o que acabou desencadeando num casamento (in)feliz.

Poderíamos pensar, inclusive, caso houvesse o chamado tempo de ouro ï o tal r̂saudosismo de um passado que na verdade nunca aconteceu concretamenteà mas que se mantém no imaginário das pessoas, através de idéias positivas em torno de algo que debatemos em nosso cotidiano ï que naturalmente e historicamente a r̃elação de paixão e amorò da EF com a ciência, ou melhor dizendo, com as ciências, sempre ocorreu a partir da forte ligação com a biologia e seus conhecimentos aplicados no campo médico. Cabe-nos aqui, apenas para este momento, elucidar que essa relação sofreu seus primeiros abalos, como já é próprio da história da EF brasileira, no 
chamado ñperíodo da crise dos anos 80ò(BRACHT, 1997; SOARES et al, 1992; KUNZ, 1991).

Segundo Bracht (2007), devemos ter a compreensão de que a EF não é uma ciência. No entanto, ela está interessada nas ciências e nas explicações científicas. A EF é uma prática de intervenção e o que a caracteriza é a intenção pedagógica com que trata um conteúdo que é retirado do universo da cultura corporal de movimento ${ }^{1}$.

Sendo o movimento e a cultura corporal temas tão complexos, pode-se afirmar que a EF é composta por um emaranhado de diferentes áreas. Unir um único objeto científico para a EF, é, em nosso entender, um tanto quanto impossível, ao mesmo tempo que seria um certo reducionismo. Por isso acreditamos e compactuamos novamente com Bracht (2007) quando o mesmo menciona que a EF precisa ser mais pensada em pequenas comunidades de diálogo em torno de uma problemática teórica acordada e compartilhada a partir da cultura de movimento/cultura corporal de movimento.

Pensar a EF enquanto prática profissional e/ou pedagógica implica pensar a mesma no seu cerne utilitário dentro de um contexto cultural. Neste sentido, acreditamos que a EF na atualidade, enquanto prática profissional e/ou pedagógica atuaria de modo científico e pedagógico em ambientes onde se trabalhe com questões relacionadas ao contexto educacional/escolar (formação humana/educacional, desporto, saúde ï promoção/prevenção/proteção/recuperação, estética, recreação, lazer); bem como em outras manifestações onde se desvela a cultura corporal de movimento. Logicamente, cada uma dessas áreas de atuação a partir de seus códigos, valores, sentidos e significados peculiares (LOVISOLO, 1998).

\footnotetext{
${ }^{1}$ Apesar da diversidade de objetos centrais criados e sistematizados pela/para EF a partir da década de 80, como r̃cultura físicaò (BETTI, 1991); r̃cultura corporalò (SOARES et al, 1992); r̃cultura de movimentoò(KUNZ, 1991; 1994) e r̃ cultura corporal de movimentoò(BRACHT, 2007; BETTI, 2003), optamos por esta última denominação por considerarmos que chega-se a uma síntese possível do que se deseja/almeja para a EF, sendo um termo que se refere r̃a parcela da cultura geral que abrange as formas culturais que se vêm historicamente construindo, nos planos material e simbólico, mediante o exercício (em geral sistemático e intencionado) da motricidade humana ï jogo, esporte, ginásticas e práticas de aptidão física, atividades rítmicas/expressivas e dança, lutas/artes marciais, práticas alternativasò (BETTI, 2003, p. 9697).
} 


\section{BIOLOGIA: A CIÊNCIA MÃE DA EF}

No contexto da Filosofia e da História do conhecimento/ciências a Idade Moderna se caracterizou por grandes revoluções em termos de conhecimento em todas as áreas. Nesse período há um movimento de mudança nos modos de se ver e pensar o mundo. Deus deixa de ser o centro do universo ï teocentrismo ï e o homem ocupa seu lugar ï antropocentrismo. Para se caracterizar essa permuta o homem teve que tirar a natureza das mãos de Deus e então inventar técnicas para dominá-la e manipulá-la. $\mathrm{Na}$ menção de Fensterseifer (2001), Bacon permite a libertação do poder teológico, enquanto Descartes ajuda na conquista de libertação do homem em relação à natureza.

O ser humano na ânsia de dominar a natureza acabou percorrendo um caminho histórico que culminou com a fragmentação dos saberes construindo assim vários campos de conhecimento. Descartes deu bases a essa fragmentação de conhecimentos, pois ele acreditava que os objetos e os fenômenos só poderiam ser conhecidos a partir do fragmento de suas partes para uma posterior apropriação e compreensão de seu todo. Seu método científico era fundado nos conhecimentos da matemática e da física. Tudo que podia ser explicado a partir dele era considerado científico e válido, por outro lado tudo que não pudesse ser explicado por ele era considerado metafísico ï para além da explicação da física ï logo, era taxado como um conhecimento inferior.

Esta forma de conceber o conhecimento refletiu na forma de se ver e compreender o corpo ï e por consequência, o seu movimento. O ser humano passa a ser analisado sob o viés da anatomia, da fragmentação, do corpo morto e esquadrinhado. Nasce então a biologia e a partir dela nasce todo um modelo de analisar o corpo.

O ser humano pensado como máquina pela ciência da época acabou por dar bases fortes para a biologia humana, medicina, fisiologia e outras ciências capilares a estas. É nesta perspectiva, que segundo Fensterseifer (2001), a anatomia desmembra o corpo humano, tomando-o como um conjunto de peças (órgãos), para estudá-las melhor e explicar o todo como a soma das partes. 
Nos escritos de Soares (2001, p.50), a EF sempre esteve vinculada à saúde biológica, sendo ñprotagonista de um projeto maior de higienização da sociedade. O corpo, do qual se ocupa, é o corpo anatomofisiológico. E ele será a referência fundamental de seu desenvolvimento como prática social.ò

Fica evidenciado nesta concepção de EF, na menção de Fensterseifer (2001), sua indiferença pelo adjetivo humano associado ao movimento. Afinal, descreve o autor, o que é comparável no homem não é o fundamentalmente humano (aspectos qualitativos), pois sabemos que não há denominador comum para emoção, satisfação, prazer, alegria e felicidade, mas somente para aquilo que pode ser traduzido em números, pois para os cânones do positivismo isso é suficiente para se fazer ciência.

Apoiados em Soares (2001) e Bracht (2001), poderíamos sintetizar o histórico da relação entre EF e a ciência-mãe biologia com a nova ordem social dos séculos XVIII e XIX (novos ditames da sociedade burguesa). A medicina e a ciência em geral vão se constituindo como importantes formas que configuram o poder humano em relação ao seu meio, à sua natureza e a partir de sua cultura $\ddot{i}$ momento histórico que se caracteriza, também, pela constituição dos estados nacionais e, por consequência, seus sistemas educacionais. Com isso, vai se consolidando a ideia de que o movimento pode promover e manter a saúde, e com isso, uma nova visão de corpo, pautada pela medicina (discurso biomédico) apresenta-se como hegemônica.

Segundo Soares (2001, p.14), a EF,

seja aquela que se estrutura no interior da instituição escolar, seja aquela que se estrutura fora dela, será a expressão de uma visão biológica e naturalizada da sociedade e dos indivíduos. Ela incorporará e veiculará a idéia da hierarquia, da ordem, da disciplina, da fixidez, do esforço individual, da saúde como responsabilidade individual.

A EF surge no Brasil colônia por volta de 1800 , com o nome de ginástica e esta totalmente amparada por um modelo médico/biológico. Ela nasce com um cunho higienista/militar, pois tinha na sua base, a medicina higiênica (preocupada com a higienização) e eugênica (raça).

$\mathrm{Na}$ corte, o médico assume várias competências perante a ginástica escolar, na inspeção e educação das crianças e jovens nas escolas. O médico era tutor do professor, sendo que este ministrava a aula nas instituições 
escolares. Visando melhorar a condição de vida da população, muitos médicos assumiram uma função higienista, buscando modificar os hábitos de saúde e higiene do povo.

Nas décadas de 1920 e 1930 o militarismo se impregna mais fortemente na EF escolar brasileira, e é em escolas militares que o professor de EF passa então a ser formado. No Estado Novo (1937-1945), sob o comando de Getúlio Vargas, o governo já estende as políticas públicas com fins militares e cívicos não só para a área da EF, mas para a educação e a sociedade de modo geral.

Em 1938, o decreto ㄲo. 21241 coloca o higienismo no seu auge ao proibir a matrícula de educandos com estado patológico para aulas de EF nos cursos secundários. Em 1939, Waldemar Areno recomenda a esterilização tanto masculina como feminina das pessoas com deficiência (SOLLER, 2005).

Nas décadas posteriores, a EF escolar começa a se desenvolver a partir de políticas públicas voltadas também ao esporte, e isso se inicia com muita força a partir dos anos de 1960. A finalidade da EF na escola era agora o de formar atletas que pudessem subir ao pódio.

As aulas de EF passam então a ser sessões de treinamento, e os alunos que não tinham habilidades para o desporto eram excluídos.

As pesquisas em EF neste período histórico no Brasil eram permeadas por toda uma base na fisiologia, na cinesiologia, na cineantropometria, enfim, nos saberes gerados pela biologia que eram a base da medicina e de todos os seus segmentos.

A crítica que aqui fazemos ao biologicismo ${ }^{2}$ como área a fundar os conhecimentos e pesquisas na EF não está fundada num contexto territorial de área, mas sim, na redução da visão humana no contexto das práxis da EF. Consideramos o conhecimento médico/biológico importante para se compreender o humano dentro das práxis da EF, no entanto, nossa crítica vem no sentido de que a EF reduziu a compreensão de ser humano aos conhecimentos dessas áreas.

Neste sentido, queremos ressaltar que este conhecimento biológico do corpo que a EF se apropriou para assentar suas práxis, nessa trajetória onde a

\footnotetext{
${ }^{2}$ O biologicismo é compreendido aqui como uma exacerbação no uso dos conhecimentos de cunho biológico na forma de conceber o ser humano enquanto ser vivo.
} 
mesma se fundou para tentar se caracterizar como área científica, também trouxe largos benefícios à EF e às ciências, conforme as palavras de Soares (2001, p. 49):

\begin{abstract}
Este conhecimento do corpo biológico dos indivíduos, se, de um lado, teve significados de libertação, na medida em que evidenciou as causas das doenças (agora não mais entendidas como castigo divino), bem como sistematizou alguns cuidados para com o corpo, entre os quais o exercício físico; de outro lado, limitou profundamente o entendimento do homem como um ser de natureza social, cuja T̃umanidadeòprovém de sua vida em sociedade.
\end{abstract}

Hoje em dia vivemos sob a ameaça de uma concepção mecanicista de mundo e de homem, que já está sendo inclusive muito criticada sob os mais diversos campos da ciência. A constituição ontológica de corpo como máquina sem espírito autoriza a potencialização de um trabalho mecanizado que permite a subordinação do homem à ciência e à técnica, assim como à lógica da taylorização ${ }^{3}$.

A visão fragmentada desconsidera o indivíduo como ser em constante interação com a natureza e o meio sociocultural, desconsidera a visão de complexidade e de auto-eco-organização do humano. Além do mais, mecanismos não têm historicidade.

A EF ao fundar muitas de suas práxis na visão de humano como máquina estabelece esta mesma realidade. Ela desconsidera o corpo real, o corpo histórico, o corpo que clama por respeito a sua essencialidade.

O método mecanicista e racional com seu caráter positivista quantitativo forneceu a r̃coluna vertebralònão só para a $E F$, mas também para outras áreas e disciplinas se estruturarem. A Medicina, a EF e tantas outras ciências idealizadas pela Biologia fizeram emergir um conjunto de procedimentos ascéticos de corpos e de mentes. Esse conjunto disciplinar é necessário e está ligado a toda uma estrutura tecnológica e científica que está imbricada e confundida com a lógica do sistema de produção econômica.

\footnotetext{
${ }^{3}$ A taylorização é o modelo de administração científica desenvolvida pelo engenheiro Frederick Taylor que tem como base a fragmentação/racionalização do trabalho para uma melhor produção e por consequência, um melhor lucro.
} 


\section{AS CIÊNCIAS SOCIAIS E HUMANAS NO CONTEXTO DA EF: APROXIMAÇÕES NECESSÁRIAS}

Os anos de 1980 são emblemáticos para a EF brasileira, pois é nessa época que se instaura a r̃ rise da EFò Esta crise traz para o cenário da área os saberes e conhecimentos oriundos das ciências sociais e humanas, as preocupações filosóficas entram em campo e criam alguns desconfortos para com as regras do jogo. Nascia uma EF mais crítica em termos políticos, sociais, filosóficos e pedagógicos: uma EF sociocultural.

Ainda hoje se questiona e se investigam as repercussões dessa crise em algumas áreas de intervenção, principalmente aquela preocupada com a formação escolar dos sujeitos, ou seja, a EF escolar em âmbito nacional: que avanços temos hoje? O que diferencia a EF escolar de agora daquela de outrora? Como isso acontece a partir da formação de professores de EF? Que aproximações com as $\mathrm{CSOH}$ foram feitas e são possíveis? Quais as limitações disso? São questões que constantemente aparecem nas discussões acadêmicas e que ainda compõem o cenário da EF escolar brasileira.

O livro de João Paulo Subira Medina r̃a Educação Física cuida do corpo... e menteò (1983); o livro r̃Educação Física: ensino e mudançasò de Elenor Kunz (1991), e a obra r̂metodologia do ensino da Educação Físicaò de autoria de Celi Taffarel, Valter Bracht, Lino Castelani Filho, Micheli Ortega, Carmem Lucia Soares e Elizabeth Varjal, (1992); vieram apresentar uma EF mais crítica, reflexiva, superadora e emancipatória. Esses e outros livros são ainda hoje ícones dessa época de crise, que culminou na inserção das ciências sociais e humanas na EF.

Bracht (1997), um dos autores precursores deste movimento, em seu livro Educação Física e aprendizagem social abordou o papel social da EF no sistema educacional brasileiro, a questão da legitimação e da autonomia da EF no contexto escolar e o tipo de aprendizagem social que as aulas deste componente curricular propiciam aos alunos.

Uma das questões-chave de sua obra é considerar ser tarefa dos professores de EF a responsabilidade de desenvolver um corpo teórico da EF, por serem os próprios sujeitos constituintes de tal área. Segundo ele, para que isso aconteça, é necessário investigação pedagógica, diferente da que se fez 
e se vem fazendo na EF brasileira (àquela ligada à aprendizagem motora, crescimento e desenvolvimento, socialização etc.).

Bracht (1997) argumenta que a produção do conhecimento na/para a EF sempre esteve pautada no âmbito das ciências naturais de matriz positivista, e isso pode ser apontado como um problema.

Ao longo dos últimos trinta anos, com a instauração da tal crise da $E F$, muito se discutiu ï e ainda se discute ï sobre a identidade da EF. A nosso ver, por consenso ou não, mas a partir daquilo que se coloca como uma identidade em relação ao senso comum que relaciona a EF a um saber fazer, parece-nos óbvio que essa identidade se sustenta via esporte e via saúde, fazendo a EF ser o que é.

Considerando-se que esporte e saúde, isoladamente, não podem ser confundidos simplesmente com a EF, como outrora, por exemplo, a ginástica já foi (ou atualmente, por vários motivos, o jogar bola ou a recreação ainda se configuram como a r̃aula de EFò, temos aí excelentes recursos para buscar aproximações com as $\mathrm{CSOH}$ já que o senso comum precisa ser contextualizado tanto em relação àquilo que a EF pode (e deve) fazer ao se identificar com esses elementos (saúde e esporte) na escola, por exemplo, bem como a iminente necessidade da sociedade, em seu todo, olhar para tais questões de maneira mais problemática e aprofundada e menos simplista.

Que exemplos poderíamos elencar sobre o que estamos tratando aqui? Poderíamos iniciar com, talvez, o mais óbvio, que associa a prática esportiva à saúde. Na tentativa de aproximar os conteúdos, saberes e práticas desses dois elementos históricos/atuais da EF, esporte e saúde, estes poderiam ser tratados sob o viés, por exemplo, da Saúde Coletiva, um campo do conhecimento recente, multidisciplinar, que dentre tantas questões, reflete em relação às questões sociais, econômicas e culturais como sendo intervenientes ou determinantes no processo saúde-doença. Não se desconsidera o biológico, o físico, o saber médico. Tampouco se hiper-dimensiona o social ou o político. Simplesmente passa-se a pensar determinados problemas atuais como decorrentes de um processo coletivo, histórico e sócio-cultural.

$\mathrm{Na}$ tentativa de ilustrar com exemplificações, apresentamos algumas possibilidades de aproximação (seja na prática/na investigação/nas teorizações da $\mathrm{EF})$, com o referencial das $\mathrm{CSOH}$. A educação que é realizada, via corporal, 
pode ser analisada pelo viés tanto da antropologia como da sociologia, bem como da história. O esporte, com sua origem a partir de um momento de transformação da sociedade (urbanização, industrialização e formação da burguesia), e a continuação dessas mudanças, via processos de mercadorização, individualização, espetacularização ï coloca-se como importante e necessário eixo de análises que aproximam as $\mathrm{CSOH}$ da EF. As danças, as lutas, as práticas corporais e sua diversidade merecem um tratamento a partir dessas outras ciências em busca de uma formação humana mais sólida, crítica e consciente.

A Antropologia, geralmente com sua abordagem microssocial, pode nos ajudar a alargar o discurso sobre nós mesmos, sobre quem somos, aproximando e distanciando de nossas próprias práticas, abrindo a perspectiva para a diversidade que nos caracteriza como humanos.

A Sociologia, por sua vez, com suas questões sociológicas e o exercício de crítica ao senso comum, pode ser uma grande aliada ao possibilitar, por exemplo, os entendimentos do sujeito em relação à sociedade, o olhar crítico e macrossocial aos fenômenos que já estão naturalizados sob nossos olhares e entendimentos.

Outra importante ciência que pode ser aproximada ao campo da EF é a História. Sabemos que, historicamente, a EF sempre foi vista como constituinte do campo da saúde, e por isso, geralmente acompanhou a forma positivista da produção do conhecimento, pautada a partir do olhar das ciências naturais. Conhecer, apreender, refletir e utilizar os conhecimentos das $\mathrm{CSOH}$ torna-se tarefa necessária à EF que perspectiva, principalmente no ambiente escolar, indivíduos críticos, autônomos e esclarecidos.

Como menciona Vaz (2008, p.79-80):

Todo aquele que atuará profissionalmente no ensino e na orientação de práticas corporais escolares, no lazer, nos esportes, na ñpromoção da saúdeò entre outras possibilidades, deve ter a experiência da pesquisa em sua formação para que possa empregar suas estratégias sistematicamente em seu trabalho profissional. Não é preciso tornar-se pesquisador, mas é importante ter a dimensão da pesquisa na formação para que a atividade profissional não seja mera repetição de fórmulas. 
Essa mesma opinião também é encontrada em Meksenas (2002, p.16):

Aos profissionais do ensino já não basta transmitir conteúdos por meio das relações de ensino e aprendizagem. Mais e mais é importante que professores, pedagogos e administradores da educação assumam o papel de construtores do conhecimento. Para tanto, é fundamental não dissociar o ensino da pesquisa, percebendo na interação dessas duas atividades o complemento que torna a educação possível.

Assim, vemos como necessária a aproximação da EF com as $\mathrm{CSOH}$ e, mesmo que em poucas linhas, esperamos ter apresentado possibilidades que continuem a direcionar a EF aos caminhos mais socioculturais na dimensão de suas investigações.

\section{LICENCIATURA E BACHARELADO: ÓFILHOS DE UM CASAMENTO INFELIZô}

Sistematizamos, aqui, algumas reflexões em torno das implicações históricas ao campo da formação profissional da EF. Em especial, referimo-nos à divisão e diferenciação nas formações profissionais, entre licenciatura (cuja formação acadêmica possibilita o acesso ao mercado de trabalho escolar) e bacharelado (na qual a formação profissional possibilita a atuação em clubes, academias, empresas privadas e como personal trainer) cursos estes que aqui, de maneira metafórica, tratamos como os r̃dois filhos de um casamento (in)felizò uma referência ao texto de Bracht (2007), que tratou da complicada relação ï ou tentativa ï de casar a EF enquanto ciência autônoma.

Estes questionamentos nos parecem pertinentes numa era onde diversos cursos de EF em nível superior no país se deparam com a urgente necessidade de reformular seus currículos. E o problema parece emperrar novamente na sua histórica crise de definição identitária agora permeada sob os signos da licenciatura/bacharelado. Essas duas perspectivas de formação acadêmica em nível de graduação enfrentam tênues limites de conceituação epistemológica. Mas muito mais que isso, elas são atravessadas por relações e jogos de poder movidos pelas tensivas geradas pelos fundamentos ideológicos e praxiológicos de uma prática profissional frente ao sistema econômico do chamado mercado de trabalho. 
É perceptível em várias instituições universitárias nos depararmos com sujeitos que discutem um currículo adequado para cada formação sem que se chegue a um consenso. Para Silva e Zoboli (2010) isso se dá, pois:

Cada vez mais se torna difícil separar o bacharel do licenciado simplesmente pelos espaços não-escolares e escolares, respectivamente, no que implica a noção de ensino como mera aplicação ou transmissão de conteúdos conceituais, procedimentais e atitudinais à classe estudantil. Sendo assim, não podemos aceitar argumentos que justifiquem e impõem diferenças entre os currículos de licenciatura e de bacharelado pela ausência ou presença de disciplinas como anatomia, didática, fisiologia, sociologia, biomecânica, filosofia. Ou ainda, que cada uma dessas devem ser transmitidas de modo mais aprofundando em um e de forma mais superficial em outro currículo.

Se tem fisiologia na grade curricular, então é bacharelado; se tem filosofia, então é licenciatura. E assim a EF fica novamente presa a seu pragmatismo monodisciplinar e consegue mais uma vez retroceder.

Aqui, trataremos da perspectiva de investigação científica para a EF, separada, agora, entre licenciatura e bacharelado como se fossem os rólois filhosò resultante desse r̃casamento (in)felizò que em plena juventude, forçosamente, são obrigados a se afastarem.

Vaz (2008, p.87), ajuda-nos a pensar sobre isso:

A Educação Física não é uma ciência, nem precisaria ser, mas uma área acadêmica cujo foco principal é a intervenção pedagógica, na escola e fora dela, e que se serve da tradição do conhecimento ocidental para suas pesquisas. Se queremos, por exemplo, estudar a hierarquia que se forma em torno da violência corporal entre os alunos e alunas, não podemos prescindir de recursos nem das Ciências Humanas e Sociais, nem das Ciências da Saúde. O olhar interdisciplinar, teórico e metodológico, é uma exigência do objeto. Para isso é preciso dominar um instrumental de investigação adequado e saber operar com conceitos, esses instrumentos do pensamento, de forma que se possa mais bem conhecer.

Há um risco, bastante denunciado, de que ao licenciado, sua tarefa ficaria circunscrita à aplicação de métodos pedagógicos na escola, sem a necessidade de questionar ou mesmo produzir a respeito de suas práticas pedagógicas e problematizações do cotidiano. Enquanto ao bacharel ficaria a responsabilidade da produção de conhecimentos ï técnicos e instrumentais ï para ser utilizado, também, pelo licenciado em EF. Isso geraria uma hierarquia entre as duas formações/atuações, em que o licenciado se submeteria aos bacharéis. 
Conforme Meksenas (2002, p.25), ao tratar da indissociável relação entre pesquisa e ensino,

Essa concepção positivista (...) foi e continua a ser nociva à educação escolar se pensamos tal educação como um momento democrático da elaboração do ensino e da pesquisa. Nociva porque foi e ainda é responsável pelo estabelecimento de uma dicotomia: alguns devem pensar a educação escolar (pesquisadores); outros devem realizar o pensado (professores e alunos) ï ou seja, a concepção muito comum que busca a separação entre o considerado đ́rabalho intelectualôe o đrabalho manualôem educação.

É necessário, portanto, considerar a singularidade do sujeito que pesquisa, seja ele professor/pesquisador ou técnico/pesquisador ou recreacionista/pesquisador ou mesmo do personal/pesquisador ï todos, de alguma maneira, atuam como ñprofessoresòque podem rebuscar seus olhares para suas próprias especificidades e problemáticas do cotidiano profissional.

Independente da forma como será realizada a investigação, como nos alerta Goldenberg (2005, p. 13), m̃ão existe um único modelo de pesquisaò Cada pesquisa surge a partir das mais diversas motivações/interesses e está relacionada, tanto suas escolhas teóricas como seus procedimentos metodológicos, com a experiência de vida do seu ator principal, (o pesquisador), que dá um tom particular àquilo que investiga.

Outro aspecto que merece atenção refere-se às experiências do pesquisador, ou seja, há um repertório de experiências anteriores, valores, sentidos e significados, intenções, racionalidades e subjetividades que marcam as intencionalidades, as tensões e escolhas quando se pretende investigar um determinando fenômeno/evento. Isso deve ser levado em conta a partir do princípio do educar pela pesquisa preconizado por Demo (2003), para o qual o pesquisador desenvolva sua pesquisa com princípios científico e educativo e a tenha como atitude cotidiana.

Independente da característica da pesquisa ï quantitativa ou qualitativa ï nenhuma ré totalmente controlável, com início, meio e fim previsíveis. A pesquisa é um processo em que é impossível prever todas as etapas.ò (GOLDENBERG, 2005, p. 13). Pesquisar é um exercício de constantes ajustes, adaptações, flexibilidade e adequação, não só com relação ao que o empírico nos apresenta como também aos aspectos teóricos e metodológicos que escolhemos e que aos poucos vamos nos aprofundando. 
Considerando-se todas essas reflexões, poderíamos pensar que esses dois irmãos, embora separados atualmente, podem aproximar-se das $\mathrm{CSOH}$, sem abandonar ou mesmo refutar os conhecimentos advindos daquela que é considerada a ciência-mãe da EF ao longo de sua história (a biologia ou o saber biomédico), acreditando numa perspectiva que seja coerente com as descobertas e não apenas com o pragmatismo das comprovações científicas, muitas vezes caras às áreas do conhecimento.

\section{CONSIDERAÇÕES FINAIS}

Em meio a crises e atritos de cunho político/ideológico mediados pela ruptura do convívio até então tolerável entre os rõlois filhos do casamento (in)felizòoptamos por retratar o que percebemos sobre o contexto da pesquisa na EF ï seja na roupagem do bacharelado ou da licenciatura ï sem nos ater a posicionamentos favoráveis ou desfavoráveis.

Porém, ambas as atitudes não são despolitizadas, pois partem de dois sujeitos que acreditam na tensiva e no diálogo respeitoso no ato de se fazer pesquisa numa área que ainda carece de seriedade acadêmica e profundidade teórica. As pesquisas em EF serão mais reconhecidas quando realmente nos apropriarmos com seriedade e rigor acadêmico das outras áreas para sustentarmos as problemáticas de nossos objetos.

Intrínseco a isso faz-se necessário reconhecer que o conhecimento é transdisciplinar e a partir desse entendimento é preciso sempre reconhecer que a resposta dada a um problema de pesquisa fundada a partir de uma ciência é sempre uma resposta insatisfatória e que por isso, esse saber gerado por essa ciência precisa ser visto como possibilidade e não como verdade absoluta, uma constante infinitude ao que se pretende investigar e aos achados das pesquisas que realizamos.

Seja a pesquisa um instrumento/ferramenta a construir grandes pontes de conhecimento e não uma arma que anuncie algum prelúdio de morte para a área que tanto prezamos. 


\section{REFERÊNCIAS}

BETTI, M. Educação física e sociedade. São Paulo: Movimento, 1991.

. (org.). Educação Física e mídia: novos olhares, outras práticas. São Paulo: Hucitec, 2003.

BRACHT, V. Educação Física e aprendizagem social. 2a . edição. Porto Alegre: Magister, 1997.

. Saber e fazer pedagógicos: acerca da legitimidade da Educação Física como componente curricular. In: CAPARRÓZ, F.E. (org.). Educação Física escolar: política, investigação e intervenção. Vitória: Proteoria, 2001, p.67-79.

Educação Física e ciência: cenas de um casamento (in)feliz. $3^{\circ}$ ed. ljuí: Unijuí, 2007.

DEMO, P. Educar pela pesquisa. 6ㄹ. Ed. Campinas: Autores Associados, 2003.

FENSTERSEIFER, P.E. A Educação Física na crise da modernidade. ljuí: Unijuí, 2001.

GOLDENBERG, M. A arte de pesquisar: como fazer pesquisa qualitativa em Ciências Sociais. Rio de Janeiro: Record, 2005.

KUNZ, E. Educação Física: ensino e mudanças. ljuí: Unijuí, 1991. . Transformação didático-pedagógica do esporte. ljuí: Unijuí, 1994.

LOVISOLO, H. A paisagem das tribos na Educação Física. In: Lecturas: Educación Física y Deportes. Buenos Aires, año 3, n. 12, diciembre 1998. 
MEKSENAS, P. Pesquisa social e ação pedagógica. São Paulo: Loyola, 2002.

SILVA, R.I.; ZOBOLI, F. Reforma curricular: tensão entre bacharelado e licenciatura na Educação Física. In: II Congresso Nacional de Educação. Anais..., Ponta Grossa/PR, 2010.

SOARES, C.L. et al. Metodologia do Ensino da Educação Física. São Paulo: Cortez, 1992.

SOARES, C.L. Educação Física: raízes européias no Brasil. 2 ed. Campinas: Autores Associados, 2001.

SOLLER, R. Educação Física inclusiva na escola: em busca de uma escola plural. Rio de Janeiro: Sprint, 2005.

VAZ, A.F. A pesquisa como prática pedagógica: uma resposta à pergunta iPesquisa em Educação Física: para quê e para quem?ò Motrivivência, Florianópolis, n.5, 6 e 7, p.60-2, julho/1994. - Sobre a relação ensino-pesquisa na formação inicial em Educação Física. Motrivivência, Florianópolis, ano XX, n.30, p.76-90, jun./2008.

\title{
THOUGHTS AND PROBLEMATIZATION ABOUT PHYSICAL EDUCATION RESEARCH: PERSPECTIVES TO THE ÓCHILDREN FROM A (UN)HAPPY MARRIAGE CHILDRENô
}

\begin{abstract}
:
This essay aims to establish some reflection about the research on the Physical Education (PE) field from its historical implications, considering the division in professional formation (teaching graduation/bachelor degree), courses that, on this text, are called r̃ hildren from a (un)happy marriageò that, in full ñouthò taken by political and marketing forces, was carried away from each other, creating and sustaining two research spots of knowing and interventions in the context of the brazilian PE. Believe it $\hat{\Phi}$ necessary to establish respectful
\end{abstract}


dialogue between the two parts when think about a research in an area that needs academic seriousness and theoretical depth.

Keywords: Physical Education Research. Teaching graduation curses. Bachelor degree courses.

\section{REFLEXIONES Y PROBLEMATIZACIONES SOBRE LA INVESTIGACIÓN EN EDUCACIÓN FÍSICA: PERSPECTIVAS PARA LOS ÓHIJOS DEL CASAMIENTO (IN)FELIZô}

\section{RESUMEN:}

Este ensayo tiene como objetivo establecer reflexiones entorno de las investigaciones en el campo de la Educación Física (EF) com sus implicaciones históricas, considerando la división en las formaciones profesionales (licenciatura/bachillerato), cursos que hacemos alusión como siendo los r̃dos hijos del casamiento (in)felizò que en plena ñuventudò fueron, por fuerzas políticas y mercadológicas, separados entre si, creando y sustentando dos nichos de investigación, saberes y intervención en el contexto de la EF brasilera. Creemos que es necesario el diálogo respetuoso entre las partes en el acto de investigar en un área que todavia carece de seriedad académica y profundidad teórica.

Palabras-clave: Investigación en Educación Física. Licenciatura. Bachillerato.

\section{Endereço para correspondência:}

Cristiano Mezzaroba

E-mail: cristiano_mezzaroba@yahoo.com.br 